\title{
A Critical Analysis of the Semiotic Engineering Evaluation Methods
}

\author{
Silvia Amelia Bim \\ Departamento de Informática - PUC-Rio. Rua Marques de São Vicente, 225 RDC. CEP 22453- \\ 900. Rio de Janeiro - RJ. Brazil. \\ sabimainf.puc-rio.br \\ http://www.inf.puc-rio.br/ sabim
}

\begin{abstract}
Semiotic Engineering is a semiotic theory of HCI that views humancomputer interaction as a contingent process of designer-to-user metacommunication. The theory currently has two evaluation methods, Communicability Evaluation and Semiotic Inspection. The aim of our research is to do a critical analysis of both methods in order to align them with each other, especially in ontological and epistemic terms, and to position them more clearly in the Semiotic Engineering territory.
\end{abstract}

Keywords: Semiotic Engineering, Evaluation Methods, Communicability Evaluation Method, Semiotic Inspection Method.

\section{Introduction}

Semiotic Engineering [1] is a semiotic theory of HCI which takes a metacommunication perspective on human-computer interaction [2]. A system's interface, along with the interaction patterns enabled by it, is characterized as a message sent from the system's designer to the system's user through the system's interface. Metacommunication stems from the fact that this message communicates how and what for users can themselves communicate with the system.

Semiotic Engineering defines "communicability" as the central quality of interest for the theory. Formally, "communicability is the distinctive quality of interactive computer-based systems that communicate efficiently and effectively to users their underlying design intent and interactive principles" [5]. In this research we are dealing with two evaluation methods proposed in association with Semiotic Engineering: the Communicability Evaluation Method (CEM) and the Semiotic Inspection Method (SIM). CEM and SIM are both qualitative and interpretive methods [3]. CEM focuses on the reception of the message sent by the designer to the user based on empirical evidence. SIM, on its turn, focuses on the emission of the metacommunication message, by analyzing the internal consistency and cohesiveness of the communicative strategies encoded in a system's interface, as well as its external consistency with a statement of the design intent. It is thus an analytical method. 


\section{Research Hypothesis, Expected Contributions and Methods}

Our research hypothesis is that, although they have some clear distinctions not only in perspective but also in terms of produced results, CEM and SIM have important relations with one another to the extent that SIM may, in some contexts of evaluation, be carried out as a step of CEM. However, because both methods characterize the same phenomenon, communicability, but are themselves in different stages of maturity (CEM was formulated in 2000, and SIM in 2006), it is important to align them with each other and to position them as clearly as possible in the Semiotic Engineering territory. Our hypothesis here is that such strict theoretical framing will allow us to obtain (by using CEM and SIM to evaluate interactive software) solid evidence of how this theory can effectively contribute with new insights for HCI.

We expect that our research results will contribute to strengthen the scientific quality of Semiotic Engineering, by promoting the feedback loop between theory and practice. Additionally, a clearer definition of CEM and SIM can certainly improve the way how they are taught, learned, and professionally practiced, which are more pragmatic contributions of this research.

In order to achieve our expected contributions, a qualitative research [4] will be conducted in three parts. The first part consists of a qualitative study through in-depth interviews with open-ended questions [6], aiming at understanding the experience of different groups with the methods, and the meanings assigned by groups and individuals to their experience. The second part consists of a number of experiments with the methods themselves. They will be used in various types of contexts in order to help us identify ease and difficulty in applying them. The third part of the research consists of a critical analysis and comparison of results obtained in the first and second parts.

Acknowledgments. Silvia Amelia Bim and Clarisse Sieckenius de Souza thank $\mathrm{CNPq}$ for research grants for carrying out this research.

\section{References}

1. de Souza, C.S.: The Semiotic Engineering of Human-Computer Interaction. The MIT Press, Cambridge (2005)

2. de Souza, C.S., Leitão, C.F., da Prates, R.O., da Silva, E.J.: The Semiotic Inspection Method. In: Proceedings of IHC-2006, SBC, Natal, RN (2006)

3. Denzin, N.K., Lincoln, Y.S.: The landscape of qualitative research: Theories and issues. Publications, Thousand Oaks, CA (2003)

4. Denzin, N.K, Lincoln, Y.S.: Handbook of Qualitative Research, 2nd edn. Sage Publications, Thousand Oaks (2000)

5. Prates, R.O., de Souza, C.S., Barbosa, S.D.J.: A method for evaluating the communicability of user interfaces. ACM Interactions 7(1), 31-38 (2000)

6. Seidman, I.: Interviewing as Qualitative Research: a guide for researchers in Education and the Social Sciences. Teachers College Press, New York (1998) 